\title{
Ground to Cloud Lightning Flash Currents and Electric Fields: Interaction with Aircraft and Production of Ionosphere Sprites
}

\author{
P. R. P. Hoole, ${ }^{1}$ S. Thirukumaran, ${ }^{2}$ Harikrishnan Ramiah, ${ }^{3}$ \\ Jeevan Kanesan, ${ }^{3}$ and S. R. H. Hoole ${ }^{4}$ \\ ${ }^{1}$ Department of Electrical and Communication Engineering, University of Technology, Lae 411, Papua New Guinea \\ ${ }^{2}$ Department of Physical Science, Vavuniya Campus of the University of Jaffna, Vavuniya 43000, Sri Lanka \\ ${ }^{3}$ Department of Electrical Engineering, University of Malaya, Kuala Lumpur 50603, Malaysia \\ ${ }^{4}$ Department of Electrical and Computer Engineering, Michigan State University, East Lansing, MI 48824, USA
}

Correspondence should be addressed to S. R. H. Hoole; srhhoole@gmail.com

Received 30 November 2013; Revised 24 June 2014; Accepted 25 June 2014; Published 3 August 2014

Academic Editor: Luis Landesa

Copyright (C) 2014 P. R. P. Hoole et al. This is an open access article distributed under the Creative Commons Attribution License, which permits unrestricted use, distribution, and reproduction in any medium, provided the original work is properly cited.

\begin{abstract}
This paper presents for the first time a case for the importance of ground to cloud (upward leader) lightning flash parameters for safety testing of direct aircraft-lightning interaction and protection of wind turbines, as well as the importance of radiated electric fields for indirect lightning-aircraft interaction and generation of electric discharges called sprites and halos in the ionosphere. By using an electric circuit model of the transverse magnetic waves along the return stroke channel, electric currents at ground level as well as cloud level are determined for both the cloud to ground lightning flash and the ground to cloud lightning flash. We show that when an aircraft triggers lightning, the electric currents will be much more severe in current magnitude, rate of rise of currents, and frequency spectrum than otherwise and are more severe than the parameters observed for the usual and well monitored (and measured) cloud to ground (downward leader) flashes. The rate of rise of currents and the frequency spectrum of the ground to cloud lightning flash are also given here. The electric fields radiated by the lightning flashes that would appear in the ionosphere are presented for both the earth flash and the ground to cloud flash.
\end{abstract}

\section{Lightning}

The majority of the lightning flashes encountered at ground are the negative, downward flashes where the lightning leader stroke emanates from the thundercloud and makes contact with the ground. Once the contact is made, the second, electrically severe return stroke-severe because it now has an ionized channel from the leader easing the flow of currentis generated at the earth end and travels along the leader channel towards the cloud $[1,2]$. These downward flash return stroke currents are measured at ground and used as standard current for testing both ground equipment and aircraft body. The other type of flash, less common, is the ground to cloud flash (upward leader and downward return stroke) which usually emanates from tall earthed structures, where the leader starts from the ground object and moves upward. Once the leader makes contact with the cloud, another downward stroke is initiated at the cloud, and by the time it reaches ground its current magnitude as well as rate of rise of currents is attenuated by the resistive components of the now ionized channel. It has been shown that the return stroke is a transverse magnetic wave [3], and it is modelled well by a travelling wave on a distributed (as opposed to lumped parameter) transmission line with resistance, inductance, and capacitance elements $[4,5]$.

Related to lightning is the generation of electrical discharges in the ionosphere, about $75 \mathrm{~km}$ above the earth. In the year 1990, these were most prominently captured by video pictures of electrical activity above a thunder cloud [6]. Sprites (named after the mischievous sprite (air spirit) Puck in Shakespeare's A Midsummer Night's Dream) are a cluster of vertical columns of electrical discharges, with downward and upward branches forming a carrot-like shape at 50 to $90 \mathrm{~km}$ altitudes $[7,8]$. Their diameters may range from a few tens to a few hundreds of meters. At altitudes between 75 and $85 \mathrm{~km} \mathrm{a}$ 


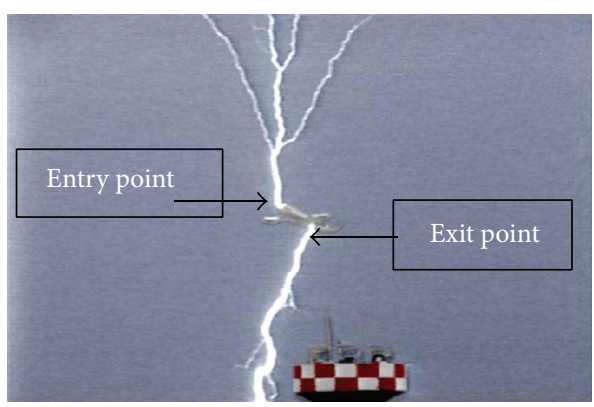

(a)

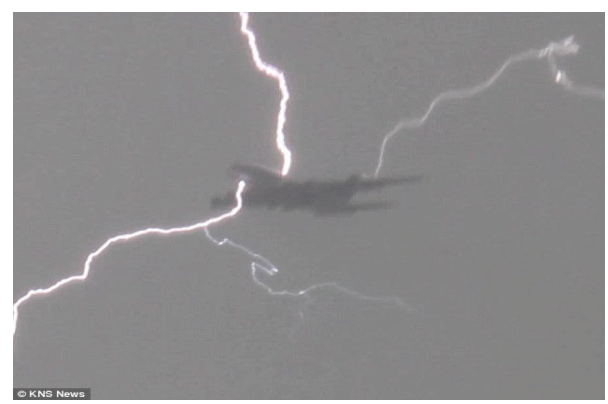

(b)

FIGURE 1: (a) Video frame of a lightning strike to an aircraft on takeoff from the Komatsu Air Force Base on the coast of the Sea of Japan during winter [1]. (b) Lightning flash incident, Heathrow Airport, May 2011 (http://www.dailymail.co.uk/news/article-1386086/Jet-strucklightning-lands-Heathrow.html\#ixzzldGEEkLOL).

diffuse region of electrical activity horizontally spreading out to 60 to $90 \mathrm{~km}$ is observed; this pancake-like diffuse region is called a halo [9]. These ionospheric, luminous, transient electric discharge phenomena close to thunderstorm activity are caused by the microsecond, transient lightning return stroke radiated electric fields, as well as the slow charge transfer from cloud to ground [10].

\section{Lightning Interaction with Aircraft}

On average a commercial aircraft is stuck by lightning once a year. One of the earliest known lightning caused aircraft disasters was in the US on December 8, 1963. Lightning directly struck the Pan Am Flight 214 aircraft causing a fuel tank explosion which killed 80 passengers including all cabin crew onboard [1]. This incident highlighted the importance of aircraft avoiding a thunderstorm environment and thus the need for early warning of an ESD environment. However, complete lightning avoidance still eludes both military and commercial aircraft, as seen for instance in Figure 1.

In Figure 1(a), an aircraft that had just taken off suffers a direct lightning strike due to the aircraft itself initiating lightning activity as it flew in an electrically charged thunderstorm environment [1]. In Figure 1(b) is shown a more recent direct strike to a commercial aircraft landing at Heathrow Airport in London. The fact that the shape of the lightning leader stroke and return stroke from aircraft to cloud is like an upright tree, whereas the lightning channel from aircraft to ground is like an inverted tree, indicates that the lightning current originated from the aircraft to cloud and from aircraft to ground. This ground to cloud-like lightning flash from aircraft to cloud indicates that modelling and computing lightning currents of cloud to ground lightning are important to better understand the currents and the electromagnetically induced transients in the aircraft electrical power and navigational and communication electronics systems. This paper does just that.

\section{Ground to Cloud Lightning and the Ionosphere}

In most cases of measured ground to cloud lightning flashes, it is thought that air breakdown initiation does not commence at stationary ground objects due to the fact that the ionized particles that gather around a ground structure in the presence of a thundercloud shield the structure from initiation of the leader stroke [11]. When it does occur, it is observed that leader initiation is due to strong radiated electric fields from lightning activity inside the cloud (intracloud lightning). This high electric field at the structure initiates the leader stroke of a ground to cloud lightning flash [12]. Similar high electric fields (e.g., $100 \mathrm{kV} / \mathrm{m}$ ) from earth flashes are associated with the production of sprites and halos in the ionosphere [10]. If the cloud of electric charges around ground structures is thought to prevent leader initiation from ground structures, it is not clear why the ionized particles that form the ionosphere do not prevent the highly luminous electric discharges (e.g., sprites) inside the ionosphere. However, it has been observed that when an external grounded or ungrounded electrode is suddenly introduced into the thundercloud-like environment, electric charges intensify around the conductor resulting in the production of leaders, as in the case of aircraft [12].

Thus from our present state of knowledge in relation to electric discharges and high current discharges from grounded objects (e.g., towers), the ionosphere and aircraft, one of the following two phenomena is necessary: (a) sudden introduction of a conductor, not allowing time for space electric charges to build up around the conductor and into a high electric field thundercloud environment or (b) high radiated electric fields from distant lightning flashes, inducing electron separations and avalanches.

Although much of the past work has concentrated on cloud to ground flashes, in this paper we show that ground to cloud (upward) lightning flashes may produce larger electric fields to imitate high current electric discharges in the ionosphere. Further, we show that an aircraft attached to an upward going lightning flash may experience more severe electric current induced stress and interference.

\section{Electric Field Simulation Results and Discussion}

Lightning simulation using the distributed transmission line model for the return stroke and the computation of transient electric fields radiated by lightning have already been 


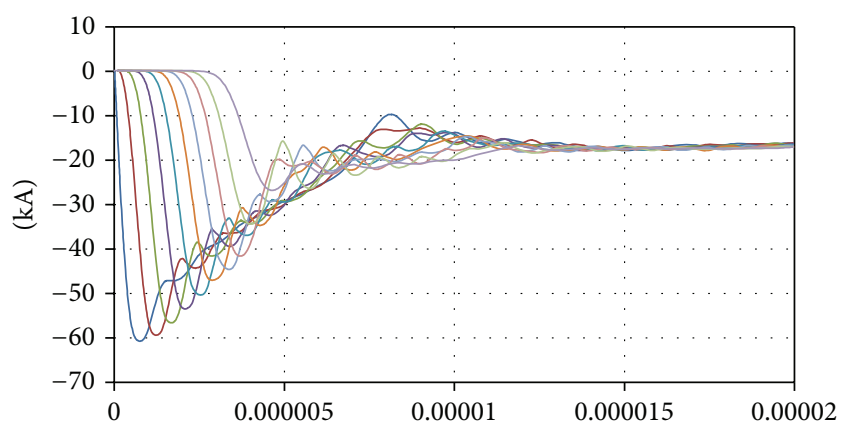

(s)

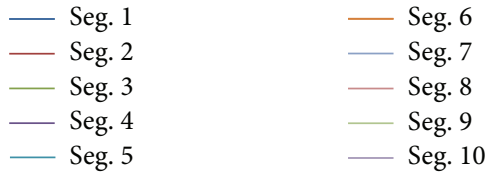

FIGURE 2: Return stroke currents for ground to cloud lightning flash, with return stroke travelling from cloud to ground.

reported elsewhere [13]. The electric fields are computed using integral solutions to electromagnetic field radiation from a transient-current carrying conductor [14, 15]. In Figure 2 is shown the computed transient electric currents of the return stroke originating from the cloud immediately after the leader makes contact with the cloud electric charge centre. The $1000 \mathrm{~m}$ long lightning channel has been divided into 10 segments of a distributed transmission line, each segment being $100 \mathrm{~m}$ long. The return stroke current originates at the cloud end of the $1000 \mathrm{~m}$ long leader channel, which is attached to the cloud and ground at its extremities. The first segment (Segment 1) is the $100 \mathrm{~m}$ transmission line element (representing the first $100 \mathrm{~m}$ of the leader channel from the cloud end) attached to the cloud, and the last segment (Segment 10) is the $100 \mathrm{~m}$ transmission line element attached to the ground (representing the $100 \mathrm{~m}$ long leader channel attached to the ground).

The cloud voltage is taken to be $50 \mathrm{MV}$, with the charge stored in a spherical charge centre at a height of $1 \mathrm{~km}$ above ground [14]. The peak electric current is about $60 \mathrm{kA}$ at the cloud level (Segment 1), dropping off to about $40 \mathrm{kA}$ at midpoint about $500 \mathrm{~m}$ above ground. The midpoint is where an aircraft would be when attached to the lightning channel. With a rise time to peak current being about $0.5 \mu \mathrm{s}$, the rate of rise of current is about $120 \mathrm{kA} / \mu \mathrm{s}$ at cloud level, and $80 \mathrm{kA} / \mu \mathrm{s}$ at midpoint. Whereas the current magnitude is associated with the heat dissipated and the force that punches large holes on structures, it is the rate of rise of currents that determines the magnitude of radiated electric fields interacting with electronic systems as well as with electric space charges inside the ionosphere.

In Figure 3 is shown the computed collapse of ground voltage of the channel towards the cloud voltage, and it is this that leads to electric charge movement from cloud to ground or to any other object attached to the channel. It is also associated with the electric charge moment $Q L$, where $L$ is the length of the channel (e.g., $1 \mathrm{~km}$ ) which produces slowly

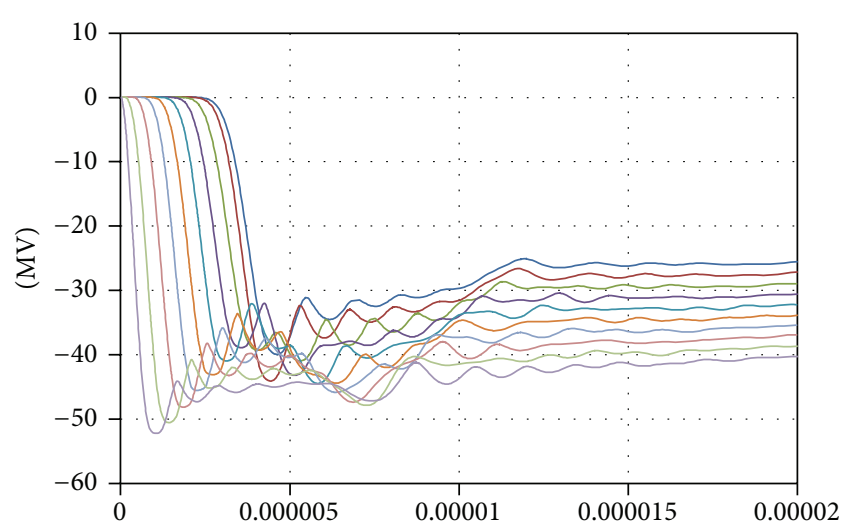

(s)

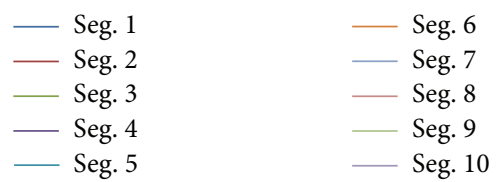

FIGURE 3: Voltage discharging by the return stroke for a ground to cloud flash.

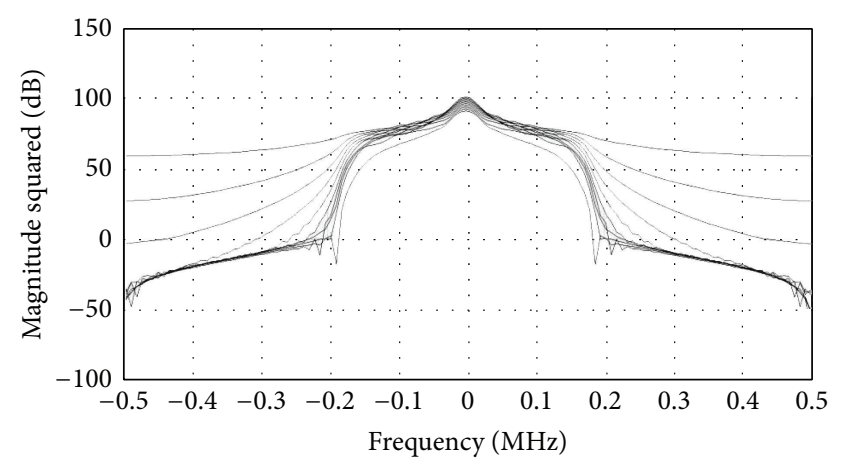

FIGURE 4: Frequency spectrum for ground to cloud flash.

varying electric fields. The frequency spectrum of the return stroke currents and the transient electric fields radiated are shown in Figures 4-6.

The frequency spectrum of Figure 4 for the currents of Figure 2 in each of the ten distributed transmission line segments is calculated to determine the significant frequencies radiated by the cloud to ground lightning flash. The spectrum is essential when designing filters and shielding for avionics. Moreover, it will determine the energy transferred to charge particles inside the ionosphere. From Figure 4 it is seen that half power bandwidth (HPBW) of cloud to ground return strokes is about $400 \mathrm{kHz}$, with significant radiation up to $500 \mathrm{kHz}$. In Figure 5 is shown the electric field almost vertically above the lightning channel, where the radiated electric field is a minimum as in the case of a dipole radiator. The effect of ground-which doubles the electric field at ground level when considered a perfect conductor-has been ignored in these plots. When the earth acts as a perfect conducting ground, at ground level, that is, at $z_{j}=0, E$ becomes $2 E \cdot z_{1}=0$ and $z_{2}=100$ indicate the vertical ( $z$-axis) 


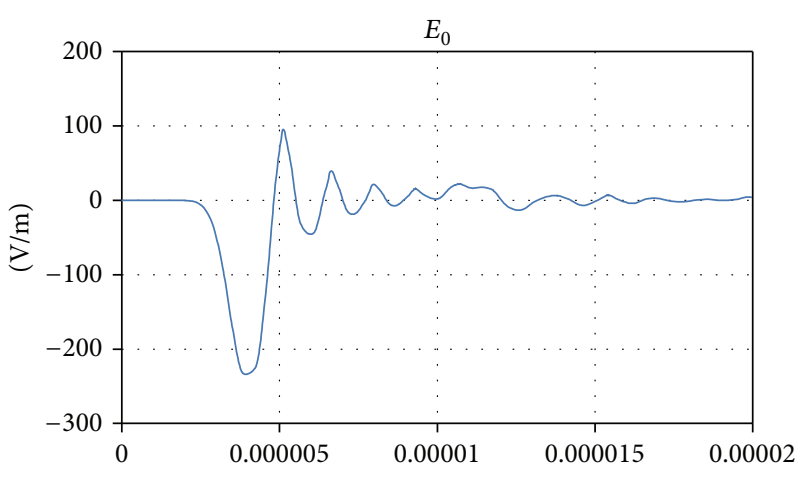

(s)

- Seg. 10

FIGURE 5: Electric field radiated by a cloud to ground flash at the ionosphere $\left(z_{1}=0, z_{2}=100, z_{j}=0, r=1000\right)$.

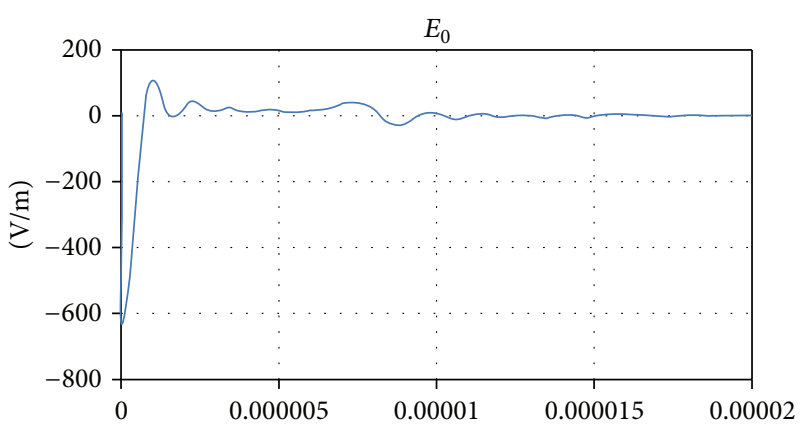

(s)

- Seg. 1

Figure 6: Electric field from a cloud to ground flash at the ionosphere $\left(z_{1}=900, z_{2}=1000, z_{j}=0, r=1000\right)$.

coordinate of the 10th line element attached to the ground, $z_{j}=0$ indicates that the observation point is on the ground, and $r=1000 \mathrm{~m}$ indicates that the observation point is $1000 \mathrm{~m}$ away from the lightning flash. Segment 10 is the last $100 \mathrm{~m}$ length of the lightning channel. It is attached to the ground. $z_{1}$ and $z_{2}$ indicate the bottom and top coordinates of a segment of the lightning.

Whereas in Figure 5 is shown the electric field radiated from the lower end of the lightning channel, in Figure 6 is shown the radiated electric field from the cloud end of the lightning channel. Segment 1 is the top $100 \mathrm{~m}$ length of the lightning channel. It is attached to the cloud. The effect of ground-which doubles the electric field at ground level when considered a perfect conductor-has been ignored in these plots as in Figure 5. When the earth acts as a perfect conducting ground, at ground level, that is, at $z_{j}=0, E$ becomes $2 E$ Although the cloud end is further away from the ground observation point $(z=0, r=1000)$; the magnitude of the electric field is almost equal to the electric field radiated from the ground end of the lightning channel; this is due to the fact that lightning return stroke currents are much larger at the cloud end. As the transient electric fields radiated are much higher because the rate of rise of currents is higher, the fields that appear at the ionosphere are higher because the cloud level currents and rates of rise currents are higher at the cloud level. The negative and positive electric fields are both high since the rates of rise of currents on the downward side of the current peak value as well as the rate of decay of currents on the upward side of the peak current are both high. This also implies that the electric fields induce an oscillating force on space electric charges in the ionosphere, as well as in semiconductor devices of electronic systems.

\section{Conclusion}

A transverse magnetic wave transmission line model of a lightning channel is used to determine the lightning return stroke currents for cloud to ground lightning flash, where the measurement of most severe return stroke electric currents and voltage profiles along the cloud end of the lightning channel are not possible (unlike the case for a cloud to ground flash, where the most severe return stroke currents at the ground level may be measured). Moreover, the radiated, submicrosecond transient electric fields and their frequency spectrum that would interact with avionics and ionospheric charged particles are calculated from the return stroke currents.

\section{Conflict of Interests}

Having undertaken this project for research purposes at a university, the authors declare that they have no conflict of interests regarding the publication of this paper.

\section{References}

[1] M. A. Uman and V. A. Rakov, "The interaction of lightning with airborne vehicles," Progress in Aerospace Sciences, vol. 39, no. 1, pp. 61-81, 2003.

[2] K. Berger, "Earth flash," in Lightning: Physics of Lightning, R. H. Golde, Ed., pp. 119-190, Academic Press, 1977.

[3] P. R. P. Hoole and S. R. H. Hoole, "Guided waves along an unmagnetized lightning plasma channel," IEEE Transactions on Magnetics, vol. 24, no. 6, pp. 3165-3167, 1988.

[4] P. Ratnamahilan, S. Ratnajeevan, and H. Hoole, "Simulation of lightning attachment to open ground. tall towers and aircraft," IEEE Transactions on Power Delivery, vol. 8, no. 2, pp. 732-738, 1993.

[5] P. R. P. Hoole, K. Pirapaharan, and S. R. H. Hoole, "Electromagnetic modeling of lightning return stroke currents: waveguide and circuit models," Journal of the Japan Society of Applied Electromagnetics and Mechanics, vol. 19, pp. S167-S170, 2011.

[6] R. C. Franz, R. J. Nemzek, and J. R. Winckler, "Television image of a large upward electrical discharge above a thunderstorm system," Science, vol. 249, no. 4964, pp. 48-51, 1990.

[7] T. Adachi, Y. Hiraki, K. Yamamoto et al., "Electric fields and electron energies in sprites and temporal evolutions of lightning charge moment," Journal of Physics D: Applied Physics, vol. 41, no. 23, Article ID 234010, pp. 1-11, 2008.

[8] W. R. Gamerota, S. A. Cummer, J. Li, H. C. Stenbaek-Nielsen, R. K. Haaland, and M. G. McHarg, "Comparison of sprite 
initiation altitudes between observations and models," Journal of Geophysical Research A, vol. 116, no. 2, Article ID A02317, 2011.

[9] V. A. Rakov and W. G. Tuni, "Lightning electric field intensity at high altitudes: inferences for production of elves," Journal of Geophysical Research D, vol. 108, no. 20, pp. 8-1-8-6, 2003.

[10] J. Qin, S. Celestin, and V. P. Pasko, "On the inception of streamers from sprite halo events produced by lightning discharges with positive and negative polarity," Journal of Geophysical Research A: Space Physics, vol. 116, no. 6, Article ID A06305, 2011.

[11] V. Cooray, Ed., Lightning Flash, IOP, Bristol, UK, 2003.

[12] V. A Rakov and M. A. Uman, Lightning Physics and Effects, Cambridge University Press, Cambridge, Mass, USA, 2003.

[13] P. R. P. Hoole and S. R. H. Hoole, "A distributed transmission line model of cloud-toground lightning return stroke: model verification, return stroke velocity, unmeasured currents and radiated fields," International Journal of Physical Sciences, vol. 6, no. 16, pp. 3851-3866, 2011.

[14] Y. Baba and V. A. Rakov, "Electric and magnetic fields predicted by different electromagnetic models of the lightning return stroke versus measured fields," IEEE Transactions on Electromagnetic Compatibility, vol. 51, no. 3, pp. 479-487, 2009.

[15] P. R. P. Hoole and S. R. H. Hoole, "Computing transient electromagnetic fields radiated from lightning," Journal of Applied Physics, vol. 61, no. 8, pp. 3473-3475, 1987. 

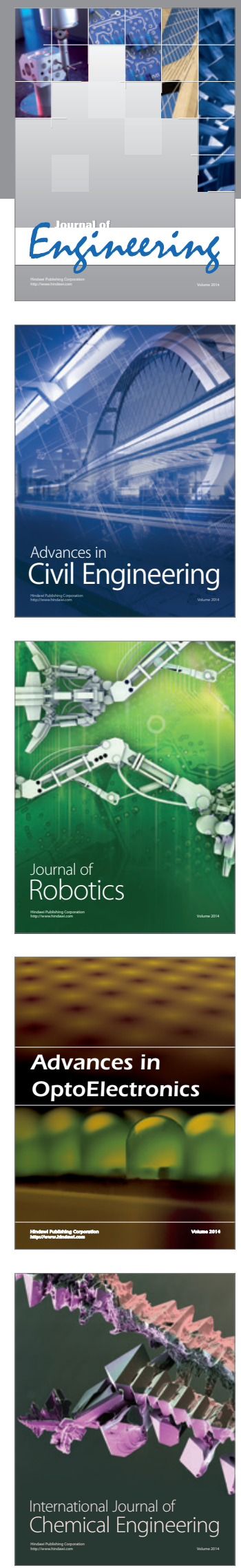

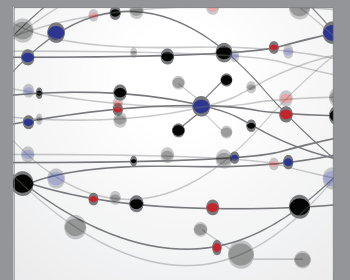

The Scientific World Journal
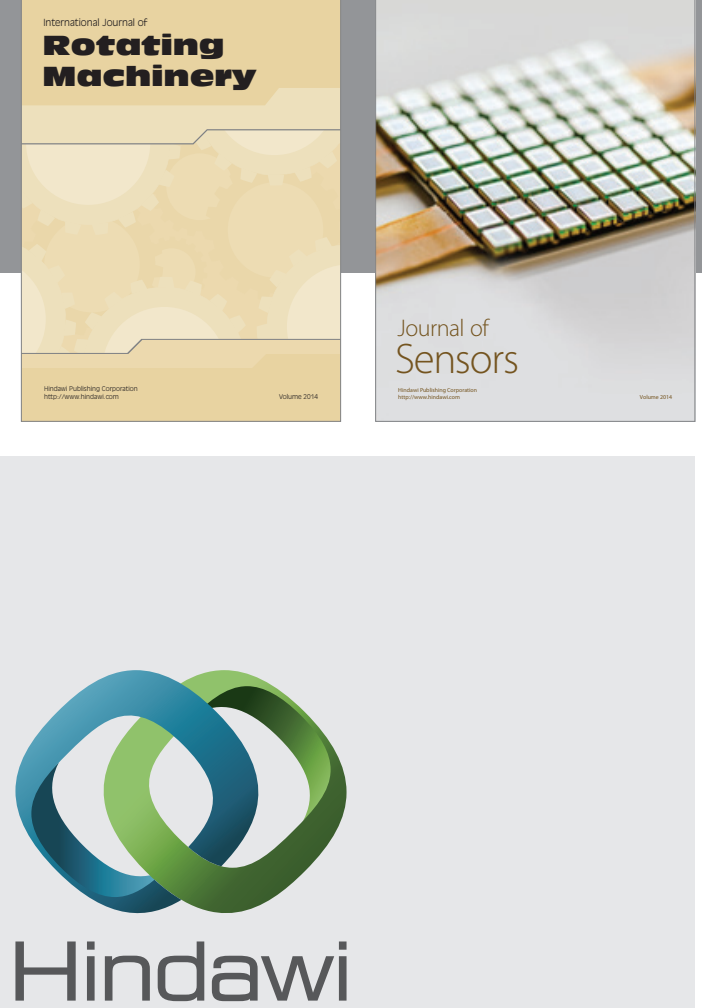

Submit your manuscripts at http://www.hindawi.com
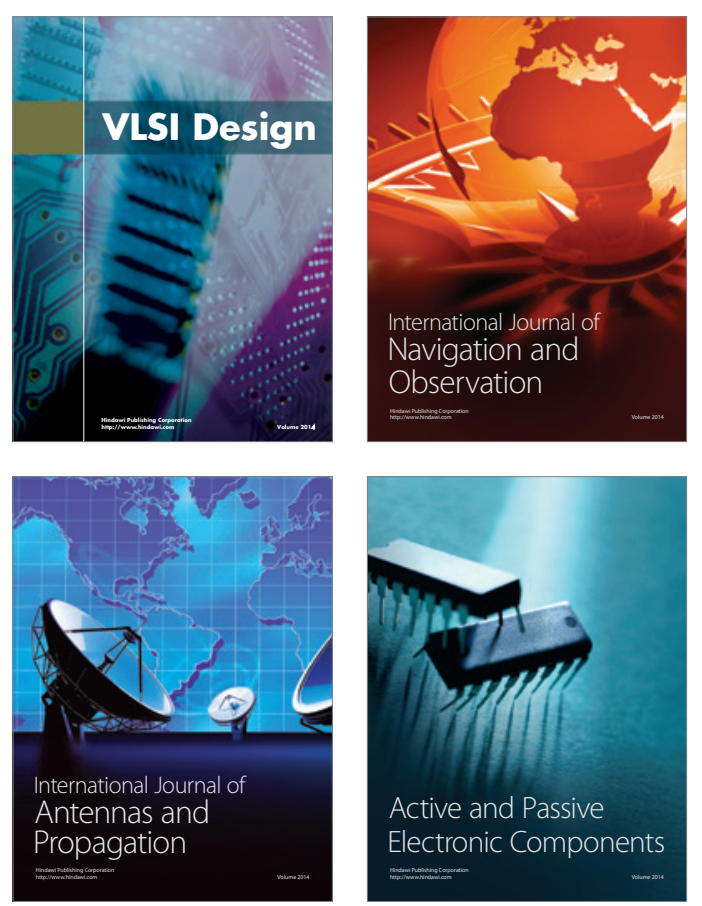
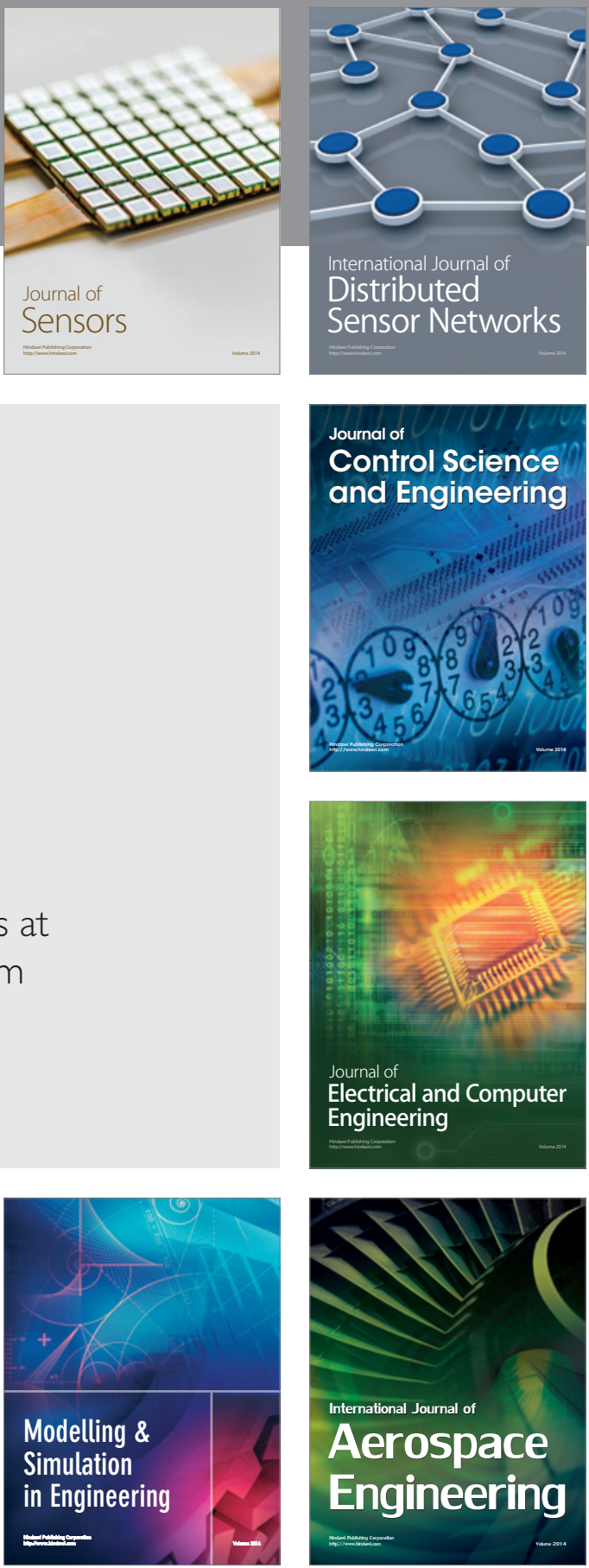

Journal of

Control Science

and Engineering
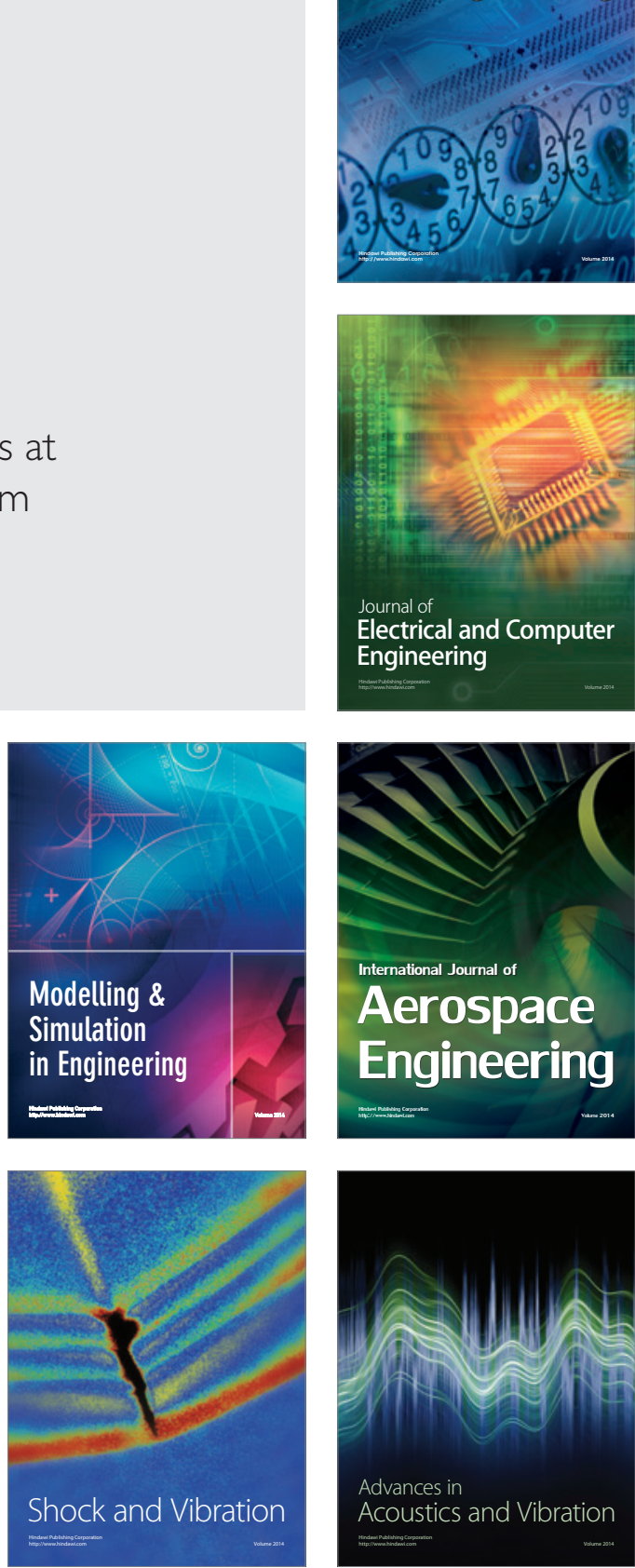